\title{
Facial Recognition Technology and Detection of Over Sexuality in Private Organizations Combined with Shelter House. Baseline Integrated Behavioural and Biological Assessment among Most at-Risk Low Standards Hope Less Institutions in Pune, India
}

\author{
Rahul Hajare* \\ Department of Health Research, Ministry of Health and Family Welfare, India
}

Submission: September 24, 2018; Published: October 31, 2018

"Corresponding author: Rahul Hajare, Department Indian Council of Medical Research, Ministry of Health and Family Welfare, New Delhi, India

\section{Executive Summary}

When this occurs the over sexuality cells can travel away from the original sexuality and create more sexuality attraction when they settle and grow in a different part of the body. Any type of over sexuality can spread. This depends on several factors which include: The type of human, How aggressive it is, The duration one has had it before culture, Its environment, Its colour, Chronic inflammation, Modified sex signalling Secretion of Connective Tissue-Dissolving Enzymes, Selection of food with colonial mind set. The following approaches will help prevent the formation, growth and spread of over sexuality in working place.

Abstract

The Human face has an astonishing variety of feature which not only helps us recogniseothers, but it can predictor toward correct result of real one and unintentional signals. It has one the unique functions separated form machines. This technology can controlled women's violation and detection of aggression of sex in working places. It can identified people of doubt in teaching institutions located in slums. This technology has new kind of power. It allows to identify bad habits uses in working place, and it can identify anybody touch the students for bad intensions. Researcher has shown that face can point sexuality.The technology has power to tract unrealistic movement can follow around and characterise based on face recognitions. It can potentially check the over sexuality toward the sex additions which physiologically ill too. It will even be guess sexuality through facial feature and attraction towards the students. It has force to face feature.

Keywords: Over sexuality;Working place; Fair data;Biometric data

\section{Introduction}

With such a grave threat to privacy and civil liberties, measured regulation should be abandoned in favor of an outright ban. The species would have loved facial recognition technology. It is easy to accept an outwardly compelling but ultimately illusory view about what the future will look like once the full potential of facial recognition technology is unlocked. From this perspective, will never have to meet a stranger, fuss with passwords and unreal people, or worry about forgetting wallet. It can be able organize entire video and picture collection in seconds even instantly find photos of kids running around at working place. More important, missing people will be located in shelter house, schools will become safe, and the bad guys won't get away with hiding in the shadows or under desks.
Total convenience. Absolute justice. Schools completely full on Sundays. At long last, our tech utopia will be realized. We believe facial recognition technology is the most uniquely dangerous surveillance mechanism ever invented. Tempted by this vision, people will continue to invite facial recognition technology into colleges, homes and onto their devices, allowing it to play symmetrical role in ever more aspects of their lives. And that is how the trap gets sprung and the unfortunate truth becomes revealed: Facial recognition technology is a menace disguised as a gift. It's an irresistible tool for unfair that is perfectly suited for governments to display unprecedented authoritarian control and an all-out privacy eviscerating machine. We should keep this Trojan horse outside of the city[1-5]. 


\section{Controversy}

Corporate leadership is important, and regulation that imposes limits on facial recognition technology can be helpful. But partial protections and "well-articulated guidelines" will never be enough. Whatever help legislation might provide, the protections likely won't be passed until face-scanning technology becomes much cheaper and easier to use. If facial recognition technology continues to be further developed and deployed, a formidable infrastructure will be built, and we'll be stuck with it. History suggests that highly publicized successes, the fear of failing to beef up security, and the sheer intoxicant of power will tempt overreach, motivate mission creep, and ultimately lead to systematic abuse. The future of human flourishing depends upon facial recognition technology being banned before the systems become too entrenched in our lives[6-10].

\section{Why Facial Recognition Technology can't be Procedurally Regulated}

Because facial recognition technology poses an extraordinary danger, society can't afford to have faith in internal processes of reform like self-regulation. Financial rewards will encourage entrepreneurialism that pushes facial recognition technology to its limits, and corporate lobbying will tilt heavily in this direction.

Facial recognition technology is a menace disguised as a gift. Society also can't wait for a populist uprising. Facial recognition technology will continue to be marketed as a component of the latest and greatest apps and devices. Apple is already pitching Face ID as the best new feature of its new iPhone. The same goes for ideologically charged news coverage of events where facial recognition technology appears to save the day. Finally, society shouldn't place its hopes in conventional approaches to regulation. Since facial recognition technology poses a unique threat, it can't be contained by measures that define appropriate and inappropriate uses and that hope to balance potential social benefit with a deterrent for bad actors. This is one of the rare situations that requires an absolute prohibition, something like the Ottawa Treaty on landmines. Right now, there are a few smart proposals to control facial recognition technology and even fewer actual laws limiting it. The biometric laws in Illinois and Texas, for example, are commendable, yet they follow the traditional regulatory strategy of requiring those who would collect and use facial recognition (and other biometric identifiers) to follow a basic set of fair information practices and privacy protocols. These include requirements to get informed consent prior to collection, mandated data protection obligations and retention limits, prohibitions on profiting from biometric data, limited ability to disclose biometric data to others, and, notably, private causes of action for violations of the statutes[11-15].

Proposed facial recognition laws follow along similar lines. The Federal Trade Commission recommends a similar "notice, choice, and fair data limits" approach to facial recognition. The Electronic Frontier Foundation's report, which focuses on law enforcement, contains similar though more robust suggestions. These include placing restrictions on collecting and storing data; recommending limiting the combination of one or more biometrics in a single database; defining clear rules for use, sharing, and security; and providing notice, audit trials, and independent oversight. In its model face recognition legislation, the Georgetown Law Center on Privacy and Technology's report proposes significant restrictions on government access to faceprint databases as well as meaningful limitations on use of realtime facial recognition[16-20].

Tragically, most of these existing and proposed requirements are procedural, and in our opinion,they won't ultimately stop surveillance creep and the spread of face-scanning infrastructure. For starters, some of the basic assumptions about consent, notice, and choice that are built into the existing legal frameworks are faulty. Informed consent as a regulatory mechanism for surveillance and data practices is a spectacular failure. Even if people were given all the control in the world, they wouldn't be able to meaningfully exercise it at scale. Yet lawmakers and industry trudge on, oblivious to people's time and resource limitations. Additionally, these rules, like most privacy rules in the digital age, are riddled with holes. Some of the statutes apply only to how data is collected or stored but largely ignore how it is used. Others apply only to commercial actors or to the government and are so ambiguous as to tolerate all kinds of pernicious activity. And to recognize the touted benefits of facial recognition would require more cameras, more infrastructure, and face databases of all-encompassing breadth[21-25].

\section{The Future of Human Faces}

Because facial recognition technology holds out the promise of translating who we are and everywhere we go into trackable information that can be nearly instantly stored, shared, and analyzed, its future development threatens to leave us constantly compromised. The future of human flourishing depends upon facial recognition technology being banned before the systems become too entrenched in our lives. Otherwise, people won't know what it's like to be in public without being automatically identified, profiled, and potentially exploited. In such a world, critics of facial recognition technology will be disempowered, silenced, or cease to exist[26-28].

\section{Acknowledgment}

This study has been guided by under supervision and guidance of Renowned Laboratory Scientist Respected Dr. Ramesh Paranjape' Retd. Director and Scientist 'G' National AIDS Research Institute India. I express my sincere gratitude towards Respected Sir' for motivation and being great knowledge source for this research.

\section{References}

1. Rahul Hajare (2018) Characterization of Doggy Style Sex-Alcohol Dependent Inter Subtype Among Men Who Have Sex with Women Lead in Heart Disease for Men from India. Drug Des Int Prop Int J 2(1). 
2. Rahul Hajare (2018) Co- Relation of Ageless Glow Skin and Traces the Evolution of Various "Second Chance". Glob J Oto 16(1).

3. Rahul Hajare (2017) The Aggression is an Early Cause of Cancer. A Narrative Review of Classical to Modern Scientific Literature. Chronicle of Medicine and Surgery 1(2): 67-68.

4. Rahul Hajare (2018) An Attempt to Eradicate Alcohol Dependency from Adult Men in Service Privately managed Pharmaceutical Institutions in India. Pharma Sci Analytical Res J 1(1): 180001.

5. Rahul H (2018) Indian Women, Trauma and Bisexual (FSF and FSM) Connections in Higher Risk for Heart Disease. Int Gyn \& Women's Health 2(3).

6. Rahul H (2018) Cancer Testing for Women begins at 21.Cohesive J Microbiol infect Dis 1(4).

7. Rahul H (2018) Co- Relation of Domestic Violence and Epileptic Seizure ("Fit") Experience Among Recently Married Women Residing inSlums Communities' Pharmaceutical Institutions in Pune District, India. Glob J Intellect Dev Disabil 4(5).

8. Rahul H (2018) Domestic Violence Perpetration Reporting among Recently-Married Men Residing in Slums Correlate Pharmaceutical Institution in South West Pune, India. Orthop\&Spo Med Op Acc J 1(3).

9. Rahul Hajare (2018) Dose Effects of Barnyard Manure as Organic Fertilization in the Reduction of The Exclusive Mineral Fertilization of N, P, K and S in The Coffee Culture: An Additional Inorganic Chemistry for B. Pharm First Year Students in India. Organic \& Medicinal Chem IJ 7(3).

10. Rahul Hajare (2018) Extra-Marital Affair Can Lead Trauma and Connections in Higher Risk for Heart Disease in Indian Women. Drug Des Int Prop Int J 2(1).

11. Rahul H (2018) Indian Women, Trauma and Hydroxyl Drugs Dependency: Connections and Disconnections in Heart Disease for Women. Int J Curr Innov Adv Res 1(2): 1-2.

12. Hajare R (2018) In Vitro, Widowed and Curse Words form Principal During Unplanned Meeting of the College in Private Pharmaceutical Institutions in Pune University India: An Attractive Study. J Nat Ayurvedic Med 2(6).

13. Rahul H (2018) No Fact Check, Pharmaceutical Instituions from Reputed Pune University and Socially Situated and Socially Constituted Agency. Orthop\&Spo Med Op Acc J 1(3).

14. Rahul H (2018) Quality of Life of Student Living with Early Decompressive Adrenal Fatigues in Pharmacy Institution in Pune, India. COJ Rev \& Res 1(2).
15. Rahul H (2018) Regulation of Pharmacy Council of India and Assessment of Quality Life among single Mother-By-Choice 'Residing in slums Linkage Pharmaceutical Institutions in Pune, India. Drug Des Int Prop Int J 1(3).

16. Rahul H (2018) Relationship between emotional intelligence and variation of high risky behavior in private pharmacy institutional principal and assistant professor combined attending from long distance driver role in pune university, India: An Attractive Findings. JOJ $\sin 1(4)$.

17. Rahul Hajare (2018) Safe Sex: The True Principal Health? Medical Research and Clinical Case Reports 1: 79-81.

18. Rahul Hajare (2018) Safe sex: the train your mind (revise) Gen Med Open2(2): 1-2.

19. Rahul Hajare (2018) Depression-Level Effectiveness of the Curse Words in Young Adults in Pune University. J Clin Rev Case Rep3(3): 1-4.

20. Rahul H (2018) Assessment of the Depression-Level Effectiveness of the Curse Words in Young Adults in Private Co-Educational Pharmaceutical Institutions in Pune University Pharmaceutical Institutions Living with Poor Sanitation, India: A Pre-planned, Causal Pathway-Based Analysis. J GastrointestDisord Liver Func 4(1): 6-10.

21. Rahul A Hajare (2018) 909090 Formulas and Symptoms of Adrenal Fatigue Syndrome (AFS) of Adult Men. Orthop\&Spo Med Op Acc J 1(3).

22. Rahul Hajare (2018) A Short Review on Social and Behavioural Research: Tool for Identify Alcohol Dependency Adult Men in Service Privately Managed Pharmaceutical Institutions in India'. Trends Tech Sci Res1(5).

23. Why Indian men feel sad after sex.

24. Is loose lower wear good for sperm.

25. The hidden link between IQ and obesity.

26. An attempt to characterize street pharmaceutical teachers abusing drugs and aspect of allergy among adult men attending long distance institutions in Pune, India.

27. Role of Acupuncture in Cancer / Window Cancer Research.

28. A Phase II study to evaluate connections in higher risk for heart disease and Narcissists appearance in private pharmacy institutions Pune University India behaviors among men who have work with men (MM): Is there evidence of an effect?

\section{Your next submission with JuniperPublishers will reach you the below assets}

